\title{
Are smokers who are regularly exposed to e-cigarette use by others more or less motivated to stop or to make a quit attempt? A cross-sectional and longitudinal survey
}

Sarah E. Jackson ${ }^{1 *}$ (D) Emma Beard ${ }^{1}$, Susan Michie², Lion Shahab1, Tobias Raupach ${ }^{2,3}$, Robert West ${ }^{1}$ and Jamie Brown ${ }^{1,2}$

\begin{abstract}
Background: Concerns have been raised that observing other people using e-cigarettes may undermine motivation to quit by renormalising smoking. This study aimed to explore associations between regular exposure to other people's e-cigarette use and motivation to stop smoking and quit attempts in smokers.

Methods: Data were from 12,787 smokers in England who participated in the Smoking Toolkit Study between November 2014 and May 2018. At baseline, respondents were asked whether anyone other than themselves regularly used an e-cigarette in their presence, whether they had made a quit attempt in the past year and how motivated they were to stop. Data at 6-month follow-up were available for 1580 respondents, who reported on whether they had attempted to quit in the past 6 months.

Results: Smokers who reported regular exposure to e-cigarette use by others were more likely than those who did not to have tried to stop smoking in the past year (32.3\% vs. 26.8\%; unadjusted RR 1.21,95\% Cl 1.11-1.31) and have high motivation to quit (16.6\% vs. 14.2\%; unadjusted RR 1.17 , 95\% Cl 1.05-1.30) but were not significantly more or less likely to make a quit attempt over the subsequent 6 months (34.4\% vs. 31.3\%; unadjusted RR 1.10, 95\% Cl 0.88-1.38). In models that adjusted for participants' own current e-cigarette use and unadjusted and adjusted models excluding current e-cigarette users from the sample, there were no significant associations between exposure to e-cigarette use by others and past quit attempts (RR 0.97-1.00), high current motivation to quit (RR 0.97-1.00) or prospective quit attempts (RR 0.94-1.12). In contrast, exposure to use of cigarettes was associated with low motivation to quit even after adjustment (RR 0.89) but not with quit attempts. Participants' own use of e-cigarette was strongly associated with high motivation to quit (RR 1.95) and past quit attempts (RR 2.14) and appeared to account for the bivariate associations with reported exposure to e-cigarettes.

Conclusion: Smokers who report regular exposure to other people using e-cigarettes are more likely to report past quit attempts and high current motivation to quit, but there does not appear to be an independent association with motivation or quit attempts after adjustment for their own current use of e-cigarettes. In contrast, reported exposure to other people using cigarettes was independently and negatively associated with high motivation.
\end{abstract}

Keywords: E-cigarettes, Motivation, Quit attempts, Prospective cohort study

\footnotetext{
* Correspondence: s.e.jackson@ucl.ac.uk

${ }^{1}$ Department of Behavioural Science and Health, University College London,

1-19 Torrington Place, London, UK

Full list of author information is available at the end of the article
}

(c) The Author(s). 2018 Open Access This article is distributed under the terms of the Creative Commons Attribution 4.0 International License (http://creativecommons.org/licenses/by/4.0/), which permits unrestricted use, distribution, and reproduction in any medium, provided you give appropriate credit to the original author(s) and the source, provide a link to the Creative Commons license, and indicate if changes were made. The Creative Commons Public Domain Dedication waiver (http://creativecommons.org/publicdomain/zero/1.0/) applies to the data made available in this article, unless otherwise stated. 


\section{Introduction}

E-cigarette use is prevalent in England, with approximately $20 \%$ of smokers currently using them and around $13 \%$ of smokers currently using at least daily [1]. Apart from their impact on the smoking behaviour of users, these devices may affect non-users in ways that are hard to predict but which may nevertheless be important for public health [2-7]. Studies have found that exposure to other tobacco smokers is a predictor of relapse [8-10] and theories of smoking addiction and cessation describe how cues play an important role in the maintenance and resumption of smoking [11]. There are concerns that exposure to e-cigarette use by others may be 'renormalising' smoking [12-16], which could reduce smokers' motivation to try to stop. However, it is also possible that seeing other people use e-cigarettes may motivate smokers to try to use these devices to help them quit. Indeed, qualitative work has indicated that many people interpret use of e-cigarettes as indicating that the user is trying to reduce or stop smoking [17]. This study examined associations between exposure to e-cigarette use by others and motivation to quit in smokers.

Evidence on the impact of exposure to e-cigarette use by others is scant, but a few experimental studies suggest that it may have an adverse influence on smokers currently attempting to quit smoking. In two studies of young adult smokers, exposure to e-cigarette use by others increased desire and urges to use e-cigarettes and smoke combustible cigarettes $[18,19]$. In another study, smokers maintained their gaze longer on pictures of e-cigarettes than on neutral pictures in a visual probe task, indicating that current smokers have an attentional bias for e-cigarette cues [20]. However, sample sizes were small and results cannot be presumed to generalise to the general population of smokers. In addition, behavioural outcomes were not assessed so the extent to which effects of e-cigarette exposure translate into differences in quitting behaviours is not known. To our knowledge, no studies have explored the impact of e-cigarette exposure in a real-world setting, and none have examined associations with motivation to stop smoking or quit attempts.

This study aimed to examine associations between reported regular exposure to e-cigarette use and (i) motivation to quit and (ii) attempts to stop smoking across smokers participating in a large population-based survey. Specifically, we were interested in:

1. The cross-sectional association between reported regular exposure to e-cigarette use and a quit attempt in the last 12 months.

2. The cross-sectional association between reported regular exposure to e-cigarette use and the prevalence of high current motivation to stop smoking.
3. The prospective association between reported regular exposure to e-cigarette use and the incidence of any quit attempt in the following 6 months.

\section{Method}

Design

The Smoking Toolkit Study is an ongoing monthly survey designed to provide information about smoking prevalence and behaviour and factors associated with cessation in England at a population level [21]. The study uses hybrid random location and quota sampling to select a new sample of approximately 1700 adults aged $\geq 16$ years each month. Participants complete a face-to-face computerassisted survey with a trained interviewer. All smokers participating between March 2014 and September 2016 who agreed to be re-contacted were telephoned 6 months after the baseline assessment to complete a follow-up survey. Data were pooled across waves to produce one sample for analysis. Full details of the baseline methods are available elsewhere, and comparisons with national data indicate that key variables such as socio-demographics and smoking prevalence are nationally representative [21].

\section{Study population}

For the present study, we used data from respondents to the survey in the period from November 2014 (the first wave to ask about regular exposure to e-cigarette users) to May 2018 (the latest wave for which data were available). Participants were included in the analyses if they reported smoking cigarettes (manufactured or hand-rolled) or any other tobacco product (e.g. pipe, cigar) daily or occasionally at the time of the baseline survey and had complete data on all variables of interest. Cross-sectional analyses were carried out on the full available sample $(n=12,787)$, and prospective analyses were carried out on the subsample for whom follow-up data were available $(n=1580)$.

\section{Measures \\ Measurement of e-cigarette exposure}

The independent variable of interest was reported regular exposure to e-cigarette use, measured at baseline. Participants were asked at baseline 'Other than yourself, does anyone regularly smoke cigarettes or use an e-cigarette in your presence, such as at your home, work, car or other places that you visit regularly?'. Responses were coded 0 for those who responded 'noneither cigarettes nor e-cigarettes' or 'yes-cigarettes only' and 1 for those who responded 'yes-e-cigarettes only' or 'yes-both cigarettes and e-cigarettes'.

\section{Measurement of outcomes}

The main outcome measures were quit attempts made in the past 12 months measured at baseline ("past quit attempts'), current motivation to stop smoking measured 
at baseline ('motivation to stop') and prospective quit attempts at 6-month follow-up ('prospective quit attempts').

Past quit attempts were assessed at baseline with the question 'How many serious attempts to stop smoking have you made in the past 12 months? By serious I mean you decided that you would try to make sure you never smoked again.' This item was coded 0 for smokers who responded that they had not made a quit attempt and 1 for those who reported one or more quit attempts.

Motivation to stop smoking was assessed at baseline using the Motivation To Stop Scale [22], a single-item measure with seven response options representing increasing motivation to quit: (1) 'I don't want to stop smoking', (2) 'I think I should stop smoking but don't really want to', (3) 'I want to stop smoking but haven't thought about when', (4) 'I REALLY want to stop smoking but I don't know when I will', (5) 'I want to stop smoking and hope to soon', (6) 'I REALLY want to stop smoking and intend to in the next 3 months' and (7) 'I REALLY want to stop smoking and intend to in the next month'. To aid interpretation, responses were dichotomised to reflect high (6-7) vs. low (1-5) motivation to stop smoking [23].

In the subsample who were invited and responded to the 6-month follow-up survey, prospective quit attempts were assessed at 6-month follow-up with the question 'How many serious attempts to stop smoking have you made in the last 6 months? By serious I mean you decided that you would try to make sure you never smoked again.' Responses were coded 0 for those who had not made a quit attempt and 1 for those who reported at least one quit attempt in the last 6 months (i.e. since the baseline survey).

\section{Measurement of potential confounders}

All potential confounders were selected a priori. Participants provided data at baseline on age, sex and social grade $(A B C 1$, which includes managerial, professional and intermediate occupations, vs. C2DE, which includes small employers and own-account workers, lower supervisory and technical occupations and semi-routine and routine occupations, never workers and long-term unemployed). We included survey year to take account of changes in the availability and regulation of e-cigarettes over the study period. Regular exposure to cigarette smoking by others was measured using the item assessing exposure to e-cigarette use described above in order to evaluate the impact of e-cigarette exposure over and above exposure to cigarette smoking. We also adjusted for participants' own current use of e-cigarettes, assessed with the item 'Are you using any of the following either to help you stop smoking, to help you cut down or for any other reason at all?', with those responding 'yes' to the option 'electronic cigarette' coded 1 and those responding 'no' coded 0 .

\section{Statistical analyses}

The analysis plan was registered on the Open Science Framework before data analysis (http://osf.io/45mux/).

We examined potential differences in baseline characteristics between the baseline sample and the subset of participants who completed the 6-month follow-up using $t$ tests for continuous variables and chi-square tests for categorical variables.

We used log-binomial regression to analyse the dichotomous cross-sectional and prospective outcomes and calculate the associated relative risk (RR) and 95\% confidence intervals (CIs). In the baseline sample of current smokers, we tested associations between e-cigarette exposure and past quit attempts and high current motivation to stop smoking. In the subset of participants who reported current smoking at baseline and responded to the 6-month follow-up questionnaire, we tested the association between e-cigarette exposure and prospective quit attempts. For all outcomes, we report bivariate associations with e-cigarette exposure and independent associations adjusting for age, sex, social grade, reported regular exposure to cigarette smoking by others, own e-cigarette use and survey year.

In order to evaluate the extent to which including current e-cigarette users in our sample affected the results, we examined associations with participants' own e-cigarette use in adjusted models and performed a sensitivity analysis excluding e-cigarette users from the sample. Where non-significant associations were found, we calculated Bayes factors (BF; planned a priori) to examine whether these associations can best be characterised as evidence of no effect, evidence of an effect or whether data were insensitive to detect an effect $[24,25]$. Alternative hypotheses were represented by half-normal distributions, and the expected effect size was set to $R R=0.7$ based on previous research into other important barriers to quit attempts [26]. We also calculated BFs with the expected effect size set to $R R=0.9$ to test sensitivity to detect small negative effects of exposure to e-cigarette use by others on motivation and quit attempts. To test sensitivity of the data to detect positive effects, we calculated BFs using the equivalent effect sizes in the opposite direction $(R R=1.3$ and $R R=1.1$ ). In order to calculate BFs using the online calculator specified in our protocol, which only allows expected effects modelled by a half-normal distribution to be expressed positively, we reran each model reversing the categorisation of e-cigarette exposure $(0=$ exposed, $1=$ not exposed $)$ and entered expected effect sizes as the natural $\log$ of 1.3 and 1.1 (as opposed to 0.7 and 0.9 ), respectively. $\mathrm{A} B F \geq 3$ can be interpreted as substantial evidence for the alternative hypothesis (and against the null), while a BF of $\leq 1 / 3$ can be interpreted as evidence for the null hypothesis. BFs between $1 / 3$ and 3 suggest that the data are 
insensitive to distinguish the alternative hypothesis from the null $[24,27]$.

In addition to our pre-registered analyses, we performed unplanned sensitivity analyses testing associations between regular exposure to e-cigarettes by others and past quit attempts, high current motivation to quit and prospective quit attempts using a four-category exposure variable, coded in line with the way the question was asked in the survey: (i) cigarettes only, (ii) e-cigarettes only, (iii) both cigarettes and e-cigarettes and (iv) neither cigarettes nor e-cigarettes (reference category). We report bivariate associations and independent associations adjusting for age, sex, social grade, own e-cigarette use and survey year.

All analyses were performed using SPSS version 25 with the exception of the Bayes factors which were calculated using an online calculator (http://www.lifesci. sussex.ac.uk/home/Zoltan_Dienes/inference/Bayes.htm).

\section{Results}

A total of 13,209 smokers were surveyed between November 2014 and May 2018, of whom 12,787 (96.8\%) provided complete data on all baseline variables. Sample characteristics are summarised in Table 1. A subset of 1580 participants $(21.9 \%$ of those participating in eligible waves) completed the 6-month follow-up survey. Comparison of those who did and did not respond to the 6-month follow-up indicated that responders tended to be older and from a higher social grade than non-responders, and fewer were exposed to cigarette smoking by others. There were no significant differences by sex, exposure to e-cigarette use by others, own use of e-cigarettes, past quit attempts or high motivation to stop smoking at baseline.

Around a quarter $(25.8 \%)$ of participants reported regular exposure to e-cigarette use by others. Smokers who were regularly exposed to e-cigarette use by others were more likely to have made a quit attempt in the past year (32.3\%) than those who were not (26.8\%; RR $1.21,95 \%$ CI $1.11-1.31, p<0.001)$. Those who were regularly exposed to e-cigarette use by others were also more likely to report high motivation to stop smoking at baseline (16.6\% vs. 14.2\%; RR 1.17, 95\% CI 1.05-1.30, $p=0.005$ ). However, exposure to e-cigarette use by others was not significantly associated with making a quit attempt 6 months later among participants who responded to follow-up (34.4\% vs. $31.3 \%$; RR 1.10, $95 \%$ CI $0.88-1.38, p=0.410$ ).

After adjustment for age, sex, social grade, exposure to cigarette smoking by others, own use of e-cigarettes and survey year (Table 2), there was no significant association between exposure to e-cigarette use by others and past quit attempts or high motivation to stop smoking. The association between exposure to e-cigarette use by others and prospective quit attempts remained non-significant. Participants' own use of e-cigarettes was the variable most
Table 1 Sample characteristics

\begin{tabular}{|c|c|c|c|}
\hline & $\begin{array}{l}\text { Baseline sample } \\
(n=12,787)\end{array}$ & $\begin{array}{l}\text { Follow-up sample } \\
(n=1580)\end{array}$ & $p^{*}$ \\
\hline \multicolumn{4}{|c|}{ Demographic characteristics } \\
\hline \multicolumn{4}{|l|}{ Age, $\%(n)$} \\
\hline $16-24$ & $19.1(2439)$ & $11.9(188)$ & $<0.001$ \\
\hline $25-34$ & $19.5(2495)$ & $13.1(207)$ & - \\
\hline $35-44$ & $15.9(2033)$ & $14.0(221)$ & - \\
\hline $45-54$ & $16.9(2163)$ & $20.5(324)$ & - \\
\hline $55-64$ & $14.7(1883)$ & $20.6(325)$ & - \\
\hline $65+$ & $13.9(1774)$ & $19.9(315)$ & - \\
\hline \multicolumn{4}{|l|}{ Sex, \% (n) } \\
\hline Men & $53.2(6799)$ & $52.5(829)$ & 0.227 \\
\hline Women & $49.8(5988)$ & $47.5(751)$ & - \\
\hline \multicolumn{4}{|c|}{ Social grade, \% (n) } \\
\hline $\mathrm{ABC1}$ & $40.3(5156)$ & $43.5(687)$ & $<0.001$ \\
\hline C2DE & $59.7(7631)$ & $56.5(893)$ & - \\
\hline \multicolumn{4}{|c|}{ Smoking characteristics } \\
\hline \multicolumn{4}{|c|}{ Exposure to e-cigarette use by others, $\%(n)$} \\
\hline No & $74.2(9484)$ & 74.6 (1179) & 0.688 \\
\hline Yes & $25.8(3303)$ & $25.4(401)$ & - \\
\hline \multicolumn{4}{|c|}{ Exposure to cigarette smoking by others, $\%(n)$} \\
\hline No & $33.6(4294)$ & $36.0(569)$ & 0.002 \\
\hline Yes & $66.4(8493)$ & $64.0(1011)$ & - \\
\hline \multicolumn{4}{|c|}{ Own e-cigarette use ${ }^{\dagger}, \%(n)$} \\
\hline No & $80.4(10284)$ & $79.0(1248)$ & 0.416 \\
\hline Yes & $19.6(2503)$ & $21.0(332)$ & - \\
\hline \multicolumn{4}{|c|}{ Past quit attempt, \% (n) } \\
\hline No & 71.8 (9178) & $71.0(1122)$ & 0.203 \\
\hline Yes & $28.2(3609)$ & $29.0(458)$ & - \\
\hline \multicolumn{4}{|c|}{ High motivation to stop smoking, \% ( $n)$} \\
\hline No & $85.1(10887)$ & $85.0(1343)$ & 0.605 \\
\hline Yes & $14.9(1900)$ & $15.0(237)$ & - \\
\hline \multicolumn{4}{|c|}{ Prospective quit attempt, \% ( $n$ ) } \\
\hline No & NA & $67.9(1073)$ & - \\
\hline Yes & NA & 32.1 (507) & - \\
\hline
\end{tabular}

*Comparison of participants who did and did not provide follow-up data ${ }^{\dagger}$ Assessed with the question: 'Are you using any of the following either to help you stop smoking, to help you cut down or for any other reason at all?'

strongly associated with past quit attempts, high motivation to stop smoking and prospective quit attempts. In addition, younger and female smokers were more likely to have made a quit attempt in the past year and to report high motivation to stop smoking. Those from a lower social grade and those who reported regular exposure to cigarette smoking by others were less likely to be highly motivated to stop smoking. Older smokers were less likely to make a quit attempt over the following 6 months. 
Table 2 Associations between exposure to e-cigarette use in others and past quit attempts, high motivation to stop smoking and prospective quit attempts

\begin{tabular}{|c|c|c|c|c|c|c|c|c|c|}
\hline & \multicolumn{3}{|c|}{$\begin{array}{l}\text { Past quit attempts } \\
(n=12,787)\end{array}$} & \multicolumn{3}{|c|}{ High motivation to stop smoking $(n=12,787)$} & \multicolumn{3}{|c|}{ Prospective quit attempts $(n=1580)$} \\
\hline & $\%[95 \% \mathrm{Cl}]$ & $\mathrm{RR}_{\text {adj }}[95 \% \mathrm{Cl}]$ & p & $\%[95 \% \mathrm{Cl}]$ & $\mathrm{RR}_{\mathrm{adj}}[95 \% \mathrm{Cl}]$ & p & $\%[95 \% \mathrm{Cl}]$ & $\mathrm{RR}_{\mathrm{adj}}[95 \% \mathrm{Cl}]$ & p \\
\hline \multicolumn{10}{|c|}{ Exposure to e-cigarette use by others } \\
\hline No & $26.8[25.9-27.7]$ & 1.00 & - & $14.2[13.6-15.0]$ & 1.00 & - & $31.3[28.7-34.0]$ & 1.00 & - \\
\hline Yes & $32.3[30.8-33.9]$ & $0.97[0.89-1.06]$ & 0.546 & $16.6[15.4-17.9]$ & $0.99[0.88-1.11]$ & 0.839 & $34.4[29.9-39.2]$ & $0.94[0.74-1.20]$ & 0.627 \\
\hline \multicolumn{10}{|l|}{ Age } \\
\hline $16-24$ & $29.8[28.0-31.6]$ & 1.00 & - & $13.6[12.3-15.0]$ & 1.00 & - & $38.3[31.7-45.4]$ & 1.00 & - \\
\hline $25-34$ & $33.1[31.3-35.0]$ & $1.10[0.98-1.24]$ & 0.094 & $17.1[15.6-18.6]$ & 1.24 [1.06-1.45] & 0.007 & $40.1[33.7-46.9]$ & $1.05[0.72-1.53]$ & 0.783 \\
\hline $35-44$ & 32.0 [30.0-34.0] & 1.05 [0.93-1.19] & 0.430 & 18.6 [17.0-20.4] & 1.34 [1.14-1.57] & $<0.001$ & 35.7 [29.7-42.3] & 0.91 [0.62-1.33] & 0.626 \\
\hline $45-54$ & 27.0 [25.1-28.9] & $0.89[0.79-1.01]$ & 0.067 & 16.4 [14.9-18.0] & 1.17 [0.99-1.37] & 0.066 & $35.2[30.2-40.5]$ & $0.92[0.65-1.30]$ & 0.629 \\
\hline $55-64$ & 24.9 [23.0-26.9] & $0.83[0.73-0.95]$ & 0.006 & 13.2 [11.8-14.8] & $0.96[0.80-1.15]$ & 0.652 & 25.5 [21.1-30.6] & 0.67 [0.47-0.97] & 0.035 \\
\hline $65+$ & 20.1 [18.3-22.0] & $0.71[0.62-0.82]$ & $<0.001$ & 9.1 [7.8-10.5] & $0.68[0.56-0.83]$ & $<0.001$ & 24.1 [19.7-29.2] & $0.65[0.45-0.96]$ & 0.028 \\
\hline \multicolumn{10}{|l|}{ Sex } \\
\hline Men & 26.9 [25.8-27.9] & 1.00 & - & 13.7 [12.9-14.6] & 1.00 & - & $31.7[28.6-35.0]$ & 1.00 & - \\
\hline Women & 29.8 [28.6-31.0] & $1.10[1.02-1.19]$ & 0.012 & $16.2[15.3-17.1]$ & $1.16[1.05-1.28]$ & 0.003 & 32.5 [29.2-35.9] & $1.02[0.83-1.24]$ & 0.877 \\
\hline \multicolumn{10}{|l|}{ Social grade } \\
\hline $\mathrm{ABC} 1$ & 29.8 [28.5-31.0] & 1.00 & - & 16.7 [15.8-17.8] & 1.00 & - & 34.6 [31.2-38.3] & 1.00 & - \\
\hline C2DE & $27.2[26.2-28.2]$ & $0.93[0.86-1.00]$ & 0.053 & $13.6[12.8-14.4]$ & $0.83[0.75-0.91]$ & $<0.001$ & $30.1[27.2-33.2]$ & 0.87 [0.71-1.07] & 0.175 \\
\hline \multicolumn{10}{|c|}{ Exposure to cigarette smoking by others } \\
\hline No & $27.8[26.4-29.1]$ & 1.00 & - & $15.7[14.6-16.8]$ & 1.00 & - & $29.7[26.1-33.6]$ & 1.00 & - \\
\hline Yes & $28.5[27.5-29.4]$ & $0.99[0.91-1.08]$ & 0.777 & $14.4[13.7-15.2]$ & $0.89[0.80-0.99]$ & 0.033 & $33.4[30.6-36.4]$ & $1.05[0.83-1.31]$ & 0.703 \\
\hline \multicolumn{10}{|c|}{ Own e-cigarette use $\mathrm{e}^{\dagger}$} \\
\hline No & $23.0[22.2-23.8]$ & 1.00 & - & $12.4[11.8-13.1]$ & 1.00 & - & $29.2[26.8-31.8]$ & 1.00 & - \\
\hline Yes & $49.8[47.8-51.7]$ & $2.14[1.97-2.33]$ & $<0.001$ & $25.0[23.3-26.7]$ & $1.95[1.75-2.18]$ & $<0.001$ & $42.8[37.6-48.1]$ & $1.44[1.14-1.83]$ & 0.002 \\
\hline Survey year & - & $1.00[0.97-1.04]$ & 0.925 & - & $1.02[0.97-1.07]$ & 0.425 & - & $0.95[0.76-1.19]$ & 0.537 \\
\hline
\end{tabular}

$R R$ risk ratio, $\mathrm{Cl}$ confidence interval

${ }^{\dagger}$ Assessed with the question: 'Are you using any of the following either to help you stop smoking, to help you cut down or for any other reason at all?'

Sensitivity analyses that did not include participants' own use of e-cigarettes as a covariate in the adjusted models produced results that were similar to the unadjusted statistics, showing significant associations between exposure to e-cigarette use by others and past quit attempts $\left(\mathrm{RR}_{\mathrm{adj}} 1.18,95 \%\right.$ CI 1.09-1.29, $\left.p<0.001\right)$ and high motivation to stop smoking $\left(\mathrm{RR}_{\mathrm{adj}} 1.17,95 \% \mathrm{CI}\right.$ 1.05-1.31, $p=0.006$ ) and no significant association for prospective quit attempts $\left(\mathrm{RR}_{\mathrm{adj}} 1.02,95 \%\right.$ CI $0.80-1.29$, $p=0.900)$.

Participants who were regularly exposed to e-cigarette use by others were more than twice as likely as those who were not to report using e-cigarettes themselves $\left(34.8 \% \quad\right.$ vs. $\left.14.3 \%, \quad X^{2}(1)=657.20, p<0.001\right)$. When e-cigarette users $(n=2503)$ were excluded from the sample, there was no significant association between exposure to e-cigarette use by others and past quit attempts $(23.0 \%$ in those exposed to e-cigarette use vs. $23.0 \%$ in those who were not) in unadjusted (RR 1.00, 95\% CI 0.90-1.12, $p=$ $0.953)$ or adjusted models $\left(\mathrm{RR}_{\text {adj }} 0.97,95 \%\right.$ CI $0.87-1.09$, $p=0.603)$. Likewise, there was no significant association with high motivation to stop smoking $(12.4 \%$ vs. $12.4 \%$; RR 1.00, 95\% CI $0.86-1.15, p=0.952$; $\mathrm{RR}_{\text {adj }} 0.97,95 \%$ CI $0.84-1.13, p=0.724)$ or prospective quit attempts $(31.9 \%$ vs. $28.6 \%$; RR $1.12,95 \%$ CI $0.84-1.48 p=0.446$; $\mathrm{RR}_{\text {adj }} 1.03$, 95\% CI 0.77-1.39, $p=0.838$ ).

Based on expected effect sizes of 0.7 and 1.3, the majority of Bayes factors indicated that the results from the adjusted models and sensitivity analyses relating to past quit attempts and high motivation to stop smoking provided moderate evidence for the null hypothesis (BF range $0.22-0.39$ for an effect size of $0.7,0.09-0.26$ for an effect size of 1.3; Additional file 1: Table S1); that is, reported regular exposure to e-cigarette use by others was not associated with decreased or increased likelihood of making a quit attempt over the past year or high motivation to stop smoking at baseline. All data relating to prospective quit attempts also marginally favoured the null hypothesis but were insensitive to detect an effect in some analyses (BF range $0.20-0.65$ for an effect size of 0.7 , 
0.29-0.91 for an effect size of 1.3). Repeating these calculations with BFs based on the expected effect sizes of 0.9 and 1.1, all outcomes were insensitive to detect small effects (range 0.39-1.18), with the exception of the adjusted model for past quit attempts in the full baseline sample which provided moderate evidence for the null hypothesis (BF 0.24).

Sensitivity analyses that used a four-category exposure variable that compared participants reporting no regular exposure to either cigarettes or e-cigarettes with those reporting regular exposure to (i) cigarettes only, (ii) e-cigarettes only and (iii) both cigarettes and e-cigarettes revealed no notable differences in results. In unadjusted models, relative to those with no exposure, those regularly exposed only to e-cigarette use by others were significantly more likely to report a past quit attempt (RR 1.33, 95\% CI 1.07-1.63) and high current motivation to quit (RR 1.45, 95\% CI 1.13-1.88), but there was no significant association with prospective quit attempts (RR 0.80, 95\% CI 0.42-1.49). After adjustment for covariates, there was no significant association between regular exposure to e-cigarette use by others and past quit attempts ( $R_{\text {adj }} 1.05$, 95\% CI 0.85-1.30), high current motivation to quit $\left(\mathrm{RR}_{\mathrm{adj}} 1.19,95 \% \mathrm{CI} 0.92-1.54\right)$ or prospective quit attempts $\left(\mathrm{RR}_{\mathrm{adj}} 0.68,95 \%\right.$ CI $\left.0.36-1.28\right)$. Complete results for the unadjusted and adjusted models are available in Additional file 2: Table S2.

\section{Discussion}

These analyses show that smokers who are regularly exposed to other people using e-cigarettes were more motivated to stop smoking and were more likely to have tried to quit, but this was not independent of their own use of e-cigarettes; in fact, there was moderate evidence for no independent association between exposure to e-cigarette use by others and motivation to stop smoking or quit attempts.

This is the first study, to our knowledge, that has assessed the impact of exposure to other people's e-cigarette use on smokers' motivation and behaviour. One in four smokers reported that someone else regularly used e-cigarettes in their presence. In contrast to experimental studies that have reported increased desire and urges to smoke in smokers exposed to e-cigarette use by others $[18,19]$, our unadjusted models were suggestive of beneficial effects of e-cigarette exposure. Smokers who were regularly exposed to e-cigarette use by others were around $20 \%$ more likely than those not regularly exposed to report being highly motivated to stop smoking in the next 3 months or to have made a serious quit attempt in the last year. One possible explanation for these discrepant findings is that the outcomes of interest in the experimental studies (desire, urges) are momentary and vary in response to features of the current environment, whereas outcomes in our study were likely to be more stable. It could also be that the impact of single exposure to an unknown person using an e-cigarette differs to the impact of regular exposure to e-cigarette use by a close social connection such as a friend, relative or colleague, particularly if the latter is known to have used e-cigarettes to successfully reduce or stop smoking [28-30]. Thus, while seeing someone use an e-cigarette may momentarily increase desire to smoke, repeated exposure to other people's e-cigarette use may draw non-users' attention to the potential utility of these devices in helping them to quit smoking, increasing their motivation to make a quit attempt.

When we adjusted for potential confounding by age, sex, social grade, survey year, reported regular exposure to cigarette smoking by others and participants' own e-cigarette use, there was no association between exposure to e-cigarette use by others and motivation or quit attempts, although exposure to cigarette smoking by others was independently associated with reduced high motivation to quit. The differences we observed in the unadjusted models were driven primarily by participants' own e-cigarette use, which was strongly associated with motivation and quit attempts and more commonly reported by smokers who were regularly exposed to e-cigarette use by others. Among smokers who did not use e-cigarettes at all, there was no evidence that exposure to other people using e-cigarettes affected motivation or quit attempts. It is possible that excluding e-cigarette users from these analyses might have overrepresented smokers who have little or no interest in e-cigarettes and who therefore might be less influenced by other people using e-cigarettes, thereby underestimating the association with e-cigarette exposure. The same pattern of results was seen when we retained e-cigarette users in the sample and adjusted for participants' own use of e-cigarettes. These findings should ease concerns about potential adverse effects of e-cigarettes on non-users' motivation and efforts to stop smoking $[15,16,31]$.

While we found no evidence that exposure to other people using e-cigarettes adversely affected smokers' motivation to stop or attempts to quit, there was a strong association between exposure to e-cigarette use by others and own e-cigarette use. Smokers who were regularly exposed to other people using e-cigarettes were more than twice as likely as those who were not to report using e-cigarettes themselves. While we cannot disentangle the direction of this association because it was not investigated longitudinally, previous research into network phenomena in smoking behaviour suggests that exposure to e-cigarette use by others might encourage non-users to take up using the devices. In a landmark paper that studied a densely interconnected social network of around 12,000 people, Christakis et al. demonstrated that smoking 
behaviour spreads through social connections, such that people are substantially more likely to smoke if they have a family member, friend or colleague who smokes and more likely to quit if a close social connection quits [32]. The effective international mass media campaign 'Stoptober' was predicated on this social contagion [33]. It is possible that the same might be true for e-cigarettes, such that having a close social connection who uses an e-cigarette may increase a person's likelihood of using the devices themselves. In a large sample of US adults who reported ever trying e-cigarettes, friends or family members using or offering e-cigarettes was cited as one of the most common reasons for trying e-cigarettes [34], and knowing people who use e-cigarettes has been shown to predict e-cigarette use in adolescent samples [35, 36]. Qualitative studies of e-cigarette users have found that the majority were introduced to e-cigarettes by friends or family who already used them [37, 38].

This study had a number of strengths, including a large sample that was representative of smokers in the English population. We used data from monthly surveys spanning 3.5 years, which limited potential bias from seasonal differences in the rate of quit attempts. Models were adjusted for a range of potential confounders that are often either not assessed in other surveys or omitted from analyses. However, there were also limitations. The assessment of quit attempts relied on recall of the last 12 months for past quit attempts and the last 6 months for prospective quit attempts, introducing scope for bias. Due to differential drop-out, the follow-up sample was not representative of the baseline sample (typically being older and from a higher social grade), which may have biased the results. In addition, the findings may not generalise to populations outside of England where tobacco control policies and regulations (e.g. the legal status of e-cigarettes) differ. The wording of the item used to assess exposure to e-cigarette use by others did not define 'regular' so this measure relies on each respondent's interpretation of regular exposure. Experimental research has indicated that smokers have an attentional bias for e-cigarette cues [20]. We did not adjust for tobacco dependence, and it is possible that highly dependent smokers might react more strongly to e-cigarette cues than smokers who are less dependent. However, previous research has found that while dependence is predictive of whether a quit attempt is successful, it is usually not associated with whether a quit attempt is made [26]. A priori we therefore decided there was not sufficient justification to warrant its inclusion as a potential confounder. Participants' own e-cigarette use was assessed with an item that asked about use 'to help you stop smoking, to help you cut down or for any other reason at all'; it is possible that the emphasis on quitting or reducing smoking may have accounted in part for the strong association we observed between own use of e-cigarettes and motivation to quit and quit attempts. However, estimates of current e-cigarette use in the Smoking Toolkit Study are extremely close to those produced by the Office for National Statistics using the Opinions and Lifestyle Survey, which uses a less prescriptive assessment [39]. Exposure to e-cigarette cues other than vaping itself (e.g. e-cigarette advertisements) was not assessed; this means that e-cigarette exposure may have been underestimated, and this study cannot inform any discussions about e-cigarette advertisements which might have an effect on smokers' motivation to stop or make a quit attempt. E-cigarette advertising in England has been tightly regulated by the EU Tobacco Product Directive since 2016. Sensitivity analyses using Bayes factors indicated that the data favoured the null hypothesis but were insensitive to detect small effects, so it is possible that regular exposure to e-cigarettes has small effects on smokers' motivation and attempts to stop smoking that were not detected in this study. It is also possible that there are effects beyond motivation and attempts. Further, qualitative research may be able to identify other important outcomes.

\section{Conclusions}

In conclusion, the concern that the surge in popularity of e-cigarettes may be renormalising smoking in England and that this may discourage smokers from trying to stop appears unsupported by our findings. Our results indicate that, in fact, smokers who are regularly exposed to other people using e-cigarettes are more likely to be highly motivated to stop smoking and more likely to have made a recent quit attempt than smokers who do not regularly encounter people using e-cigarettes. A key factor underpinning these differences seems to be that smokers who are regularly exposed to e-cigarette use by others are more likely to use e-cigarettes themselves. Independent of smokers' own use of e-cigarettes, regular exposure to other people using e-cigarettes appears to have little impact on how motivated smokers are to stop and whether they make a quit attempt. While it is important to consider these results in light of the study's limitations, in particular relating to self-reported items, having found no evidence for an adverse impact of e-cigarette exposure on non-users, these findings should offer some reassurance in terms of the wider public health impact of e-cigarettes, particularly given evidence that the alternative, cigarette smoking, may reduce other smokers' motivation to quit.

\section{Additional files}

Additional file 1: Table S1. Bayes factors for non-significant results. (DOCX $17 \mathrm{~kb}$ ) 
Additional file 2: Table S2. Unadjusted and adjusted associations between exposure to e-cigarette use in others and past quit attempts, high motivation to stop smoking and prospective quit attempts. (DOCX $21 \mathrm{~kb}$ )

\section{Abbreviations}

BF: Bayes factor; Cl: Confidence interval; RR: Relative risk

\section{Funding}

Cancer Research UK funded data collection (C1417/A22962; C44576/A19501) and SJ, EB and JB's salary (C1417/A22962). The funders had no final role in the study design; in the collection, analysis and interpretation of data; in the writing of the report; or in the decision to submit the paper for publication. All researchers listed as authors are independent from the funders, and all final decisions about the research were taken by the investigators and were unrestricted. EB's salary is partly funded by the NIHR SPHR. The views are those of the authors(s) and not necessarily those of the NHS, the NIHR or the Department of Health. SPHR is a partnership between the Universities of Sheffield, Bristol, Cambridge and Exeter; UCL; The London School for Hygiene and Tropical Medicine; the LiLaC collaboration between the Universities of Liverpool and Lancaster and Fuse; and The Centre for Translational Research in Public Health, a collaboration between Newcastle, Durham, Northumbria, Sunderland and Teesside Universities.

\section{Availability of data and materials}

The datasets used and/or analysed during the current study are available from the corresponding author on reasonable request.

\section{Authors' contributions}

SEJ, EB, SM, LS, TR, RW and JB conceived and designed the study. SEJ analysed and interpreted the data and drafted the manuscript. EB, SM, LS, TR, RW and JB revised the manuscript critically for intellectual content. All authors read and approved the final manuscript.

\section{Ethics approval and consent to participate}

Ethical approval for the Smoking Toolkit Study was granted originally by the UCL Ethics Committee (ID 0498/001) and participants provided full informed consent. The data are not collected by $U C L$ and are anonymised when received by UCL.

\section{Consent for publication}

Not applicable.

\section{Competing interests}

$J B$ and $E B$ received unrestricted research funding from Pfizer, who manufacture smoking cessation medications. LS has received honoraria for talks, an unrestricted research grant and travel expenses to attend meetings and workshops from Pfizer and has acted as paid reviewer for grant awarding bodies and as a paid consultant for health care companies. TR has received honoraria from Pfizer, Novartis, Glaxo Smith Kline, Astra Zeneca and Roche as a speaker in activities related to continuing medical education. He has also received financial support for investigator-initiated trials from Pfizer and Johnson \& Johnson. RW undertakes research and consultancy for and receives travel funds and hospitality from manufacturers of smoking cessation medications (Pfizer, GlaxoSmithKline and Johnson \& Johnson). All authors declare no financial links with tobacco companies or e-cigarette manufacturers or their representatives.

\section{Publisher's Note}

Springer Nature remains neutral with regard to jurisdictional claims in published maps and institutional affiliations.

\section{Author details}

${ }^{1}$ Department of Behavioural Science and Health, University College London, 1-19 Torrington Place, London, UK. '2Department of Clinical, Educational and Health Psychology, University College London, London, UK. ${ }^{3}$ Department for Cardiology and Pneumology, Göttingen University Medical Centre, Göttingen, Germany.
Received: 26 July 2018 Accepted: 18 October 2018

Published online: 14 November 2018

\section{References}

1. West R, Brown J. Electronic cigarettes in England - latest trends http://www smokinginengland.info/latest-statistics/. Accessed 19 June 2018.

2. Levy DT, Borland R, Villanti AC, Niaura R, Yuan Z, Zhang Y, et al. The application of a decision-theoretic model to estimate the public health impact of vaporized nicotine product initiation in the United States. Nicotine Tob Res. 2017;19:149-59.

3. Levy DT, Cummings KM, Villanti AC, Niaura R, Abrams DB, Fong GT, et al. A framework for evaluating the public health impact of e-cigarettes and other vaporized nicotine products. Addiction. 2016;112:8-17.

4. Glantz SA. Need for examination of broader range of risks when predicting the effects of new tobacco products. Nicotine Tob Res. 2017:19:266-7.

5. Kozlowski LT, Warner KE. Adolescents and e-cigarettes: objects of concern may appear larger than they are. Drug Alcohol Depend. 2017;174:209-14.

6. McNeill A, Brose L, Calder R, Bauld L, Robson D. Evidence review of e-cigarettes and heated tobacco products 2018. A report commissioned by Public Health England. London: Public Health England; 2018. https://www.gov.uk/ government/publications/e-cigarettes-and-heated-tobacco-products-evidencereview/evidence-review-of-e-cigarettes-and-heated-tobacco-products-2018executive-summary. Accessed 12 July 2018

7. Warner KE, Mendez D. E-cigarettes: comparing the possible risks of increasing smoking initiation with the potential benefits of increasing smoking cessation. Nicotine Tob Res. 2018. https://doi.org/10.1093/ntr/nty062.

8. Zhou X, Nonnemaker J, Sherrill B, Gilsenan AW, Coste F, West R. Attempts to quit smoking and relapse: factors associated with success or failure from the ATTEMPT cohort study. Addict Behav. 2009;34:365-73.

9. Lee C, Kahende J. Factors associated with successful smoking cessation in the United States, 2000. Am J Public Health. 2007;97:1503-9.

10. Li L, Feng G, Jiang $Y$, Yong $H-H$, Borland R, Fong GT. Prospective predictors of quitting behaviours among adult smokers in six cities in China: findings from the International Tobacco Control (ITC) China Survey. Addict Abingdon Engl. 2011:106:1335-45.

11. West R, Brown J. Theory of addiction. Chichester: Wiley; 2013

12. Bartter T. Electronic cigarettes: aggregate harm. Ann Intern Med. 2015;163:59.

13. de Andrade M, Hastings G, Angus K. Promotion of electronic cigarettes: tobacco marketing reinvented? BMJ. 2013;347:f7473.

14. McKee M, Chapman S, Daube M, Glantz S. The debate on electronic cigarettes. Lancet. 2014;384:2107.

15. Chapman S, Daube M, Maziak W. Should e-cigarette use be permitted in smoke-free public places? No. Tob Control. 2017;26:e3-4

16. Glantz SA, Bareham DW. E-cigarettes: use, effects on smoking, risks, and policy implications. Annu Rev Public Health. 2018;39:215-35.

17. McKeganey N, McKeganey N. Visible vaping: e-cigarettes and the further de-normalization of smoking, visible vaping: e-cigarettes and the further de-normalization of smoking. doi:https://doi.org/10.23937/2474-3631/1510023.

18. King AC, Smith LJ, McNamara PJ, Matthews AK, Fridberg DJ. Passive exposure to electronic cigarette (e-cigarette) use increases desire for combustible and e-cigarettes in young adult smokers. Tob Control. 2015;24:501-4.

19. King AC, Smith $\sqcup$, Fridberg DJ, Matthews AK, McNamara PJ, Cao D. Exposure to electronic nicotine delivery systems (ENDS) visual imagery increases smoking urge and desire. Psychol Addict Behav. 2016;30:106.

20. Lochbuehler K, Wileyto EP, Tang KZ, Mercincavage M, Cappella JN, Strasser AA. Do current and former cigarette smokers have an attentional bias for e-cigarette cues? J Psychopharmacol (Oxf). 2018;32:316-23.

21. Fidler JA, Shahab L, West O, Jarvis MJ, McEwen A, Stapleton JA, et al. "The smoking toolkit study": a national study of smoking and smoking cessation in England. BMC Public Health. 2011;11:479.

22. Kotz D, Brown J, West R. Predictive validity of the Motivation To Stop Scale (MTSS): a single-item measure of motivation to stop smoking. Drug Alcohol Depend. 2013;128:15-9.

23. Hitchman SC, Brose LS, Brown J, Robson D, McNeill A. Associations between e-cigarette type, frequency of use, and quitting smoking: findings from a longitudinal online panel survey in Great Britain. Nicotine Tob Res. 2015;17:1187-94.

24. Dienes Z. Using Bayes to get the most out of non-significant results. Front Psychol. 2014;5. https://doi.org/10.3389/fpsyg.2014.00781.

25. West R. Using Bayesian analysis for hypothesis testing in addiction science. Addiction. 2015;111:3-4 
26. Fidler JA, West R. Enjoyment of smoking and urges to smoke as predictors of attempts and success of attempts to stop smoking: a longitudinal study. Drug Alcohol Depend. 2011;115:30-4.

27. Jeffreys H. The theory of probability. Oxford: Clarendon Press; 1961.

28. Zhu S-H, Zhuang Y-L, Wong S, Cummins SE, Tedeschi GJ. E-cigarette use and associated changes in population smoking cessation: evidence from US current population surveys. BMJ. 2017;358:j3262.

29. Beard E, West R, Michie S, Brown J. Association between electronic cigarette use and changes in quit attempts, success of quit attempts, use of smoking cessation pharmacotherapy, and use of stop smoking services in England: time series analysis of population trends. BMJ. 2016;354:4645.

30. Hartmann-Boyce J, McRobbie H, Bullen C, Begh R, Stead LF, Hajek P. Electronic cigarettes for smoking cessation. Cochrane Database Syst Rev. 2016;9:CD010216.

31. Chapman S. E-cigarettes: the best and worst case scenarios for public health. BMJ. 2014;349:g5512.

32. Christakis NA, Fowler JH. The collective dynamics of smoking in a large social network. N Engl J Med. 2008;358:2249-58

33. Brown J, Kotz D, Michie S, Stapleton J, Walmsley M, West R. How effective and cost-effective was the national mass media smoking cessation campaign "Stoptober"? Drug Alcohol Depend. 2014;135:52-8.

34. Pepper JK, Ribisl KM, Emery SL, Brewer NT. Reasons for starting and stopping electronic cigarette use. Int J Environ Res Public Health. 2014;11:10345-61.

35. Anand V, McGinty KL, O'Brien K, Guenthner G, Hahn E, Martin CA. E-cigarette use and beliefs among urban public high school students in North Carolina. J Adolesc Health. 2015:57:46-51.

36. Kong G, Morean ME, Cavallo DA, Camenga DR, Krishnan-Sarin S. Reasons for electronic cigarette experimentation and discontinuation among adolescents and young adults. Nicotine Tob Res. 2015;17:847-54.

37. McKeganey N, Barnard M, Russell C. Vapers and vaping: e-cigarettes users views of vaping and smoking. Drugs Educ Prev Policy. 2018;25:13-20.

38. Wadsworth E, Neale J, McNeill A, Hitchman SC. How and why do smokers start using e-cigarettes? Qualitative study of vapers in London, UK. Int J Environ Res Public Health. 2016;13. https://doi.org/10.3390/ijerph13070661.

39. Office for National Statistics. E-cigarette use in England. 2018. https:/umw.ons.gov. uk/peoplepopulationandcommunity/healthandsocialcare/healthandlifeexpectancies/ datasets/ecigaretteuseinengland. Accessed 9 May 2018.

Ready to submit your research? Choose BMC and benefit from:

- fast, convenient online submission

- thorough peer review by experienced researchers in your field

- rapid publication on acceptance

- support for research data, including large and complex data types

- gold Open Access which fosters wider collaboration and increased citations

- maximum visibility for your research: over $100 \mathrm{M}$ website views per year

At $\mathrm{BMC}$, research is always in progress.

Learn more biomedcentral.com/submissions 